https://dx.doi.org/10.4314/ijs.v23i1.10

Ife Journal of Science vol. 23, no. 1 (2021)

\title{
ASSESSMENT OF MORPHO-VARIABILITY BETWEEN BRUCHID TOLERANT AND SUSCEPTIBLE COWPEA (Vigna unguiculata L. Walp.) ACCESSIONS
}

\author{
*Amusa, O. D. and Ogunkanmi, L. A. \\ Department of Cell Biology and Genetics, University of Lagos, Nigeria. \\ *E-mail of corresponding author: odamusa@unilag.edu.ng \\ (Received: 21 ${ }^{\text {st }}$ October, 2020; Accepted: $1^{\text {st }}$ January, 2021)
}

\section{ABSTRACT}

\begin{abstract}
Cowpea bruchid is a major constraint to cowpea production. Easy identification of resistant/tolerant accessions to bruchid infestation has been a major challenge in bruchid resistant breeding programmes. Hence, the study was aimed to evaluate variations in some morphological characters between some bruchid resistant/tolerant and susceptible cowpea accessions, correlating them with their bruchid tolerance status in the hope of identifying a pointer character(s) that can facilitate easy identification of bruchid tolerant among cowpea germplasm. Sixty accessions were collected and evaluated for bruchid tolerance. Accessions were then grouped into bruchid susceptible and bruchid tolerant. These accessions were planted in Randomized Complete Block Design with ten replicates. Morphological differences between groups were evaluated accordingly. Of the sixty accessions evaluated, fifty-two were susceptible while eight were bruchid tolerant. No qualitative differences were observed between bruchid susceptible and tolerant groups, however significant differences were observed in quantitative characters which include terminal leaflet length, terminal leaflet/width ratio, leaf petiole length, terminal leaflet petiole length (TLPL), leaf petiole length, pod length (PDL), pod width, total number of pods per plant, seed length (SDL), seed width (SDW), seed thickness (SDTK) and 100 seed weight (100SDW). Bruchid tolerance was significantly positively correlated with seed characters which include, SDL $(\mathrm{r}=0.798, p<0.01)$; SDW ( $\mathrm{r}=0.798, p<0.01)$; SDTK $(\mathrm{r}=0.758, p<0.01)$; 100SDW (0.830, $p<0.01)$ and significantly negatively correlated with TLPL and PDL $(p<0.05)$. These characters can provide easy identification of bruchid tolerant among cowpea germplasm, hence requires further investigations.
\end{abstract}

Keywords: Cowpea, Vigna unguiculata, Bruchid, Callosobruchus maculatus, Morphology

\section{INTRODUCTION}

Cowpea (Vigna unguiculata L. Walp.) is an important crop in Nigeria. Its production and storage are faced with various biotic stresses in countries where they are produced. Callosobruchus maculatus Fab., (cowpea beetle, weevil or bruchid), is not a threat on the field though infestation starts on the field, but major havoc is done in storage. It has the potential to cause high grain loss both in the quantity and quality of the stored cowpea seeds. Larvae feed on the seed content and cause about $90 \%$ of seed loss due to perforations (Amusa et al., 2014). This reduces the usefulness of the seeds and makes them unsuitable for planting or human consumption, thereby reducing their market value (Amusa et al., 2019).

There have been several attempts to preserve seeds by management practises to reduce the growth, development or reproduction of insects. These include the use of pesticides, physical and cultural control. The use of chemical pesticides has been highly effective and most used against these storage pests. However, there have been reports that the use of chemical pesticides is not only expensive but sometimes resulted in food poisoning and environmental toxicity (Olakojo et al., 2007; Keneni et al., 2011). Thus, in a collaborative research project, the International Institute of Tropical Agriculture (IITA) and John Innes Centre, UK saw the need for an alternative and better management method for this pest which protects not only the crop, but also the consumers and the environment, and attempted to genetically modify cowpea for insect pests' resistance (IITA, 1990). As a result, several improved cultivars and/or varieties of cowpea seeds with different levels of resistance to infestation by $C$. maculatus have been released to date. However, there have been reports of resistance breakdown in many of these earlier tolerant genotypes identified and/or developed (Amusa et al., 2013, 2014). This is an indication of the insects' polymorphic adaptation to the resistance stress imposed on its infestation capabilities. The identification of new 
resistant/tolerant genotypes to fight and/or suppress the menace of this pest is now of paramount importance to cowpea production in combating food insufficiency.

A major constraint in the identification of resistant/tolerant genotypes is the timeconsuming process to develop bruchid cultures and the duration of screening. An alternative is to use bruchid resistant associative characters to ease identification and/or prediction of bruchid tolerant genotypes, as this method will facilitate the rapid identification of other potential genotypes that can be used for breeding this valuable trait into the elite germplasm. Both qualitative and quantitative traits are very important in germplasm assessment, and for breeding programs as it allows the identification of available resources for selection. Hence, this study seeks to evaluate the morphological variations among sixty bruchid tolerant and susceptible cowpea accessions, and to correlate them with their bruchid tolerance status with the hope of identifying bruchid tolerant traits among cowpea germplasm.

\section{MATERIALS AND METHODS Collection of Samples}

Seeds of sixty cowpea accessions were used in this study including, twenty-nine (29) accessions collected from the International Institute of Tropical Agriculture (IITA), Ibadan, Nigeria and thirty-one (31) landraces collected from the Institute of Agricultural Research and Training (IAR\&T), Moor Plantation, Ibadan, Nigeria (Table 1).

\section{Bruchid Tolerance Evaluation}

A bruchid tolerance evaluation was carried out to determine the tolerance status of the cowpea accessions according to Amusa et al. (2014). Briefly, bruchid infested seeds collected from IAR\&T was used to establish a bruchid culture at $20-30{ }^{\circ} \mathrm{C}$ and $55-60 \%$. Two pairs of newly emerged adult insects, 1-3 day old, were introduced into petri-dishes containing 10 seeds (oven dried at $60{ }^{\circ} \mathrm{C}$ for $5 \mathrm{~h}$ ) of each cowpea accession. Insects were allowed to mate and oviposit for 3 days before removal. Four replicates of each accession were set up and arranged in a completely randomized design for 60 days. Daily adult insect's emergence was recorded for the duration of the study. To measure the level of bruchid tolerance (Tol) in cowpea genotypes evaluated, the following parameters were used: Percentage adult emergence (PAE), Percentage seed damaged (PSD) and Host susceptible index (HSI) as shown below:

$$
\begin{aligned}
& \text { (a) PAE }=\frac{\text { Number of emerged adult insects }}{\text { Number of eggs laid }} * 100 \\
& \text { (b) } \mathrm{PSD}=\frac{\text { Total number of damaged seeds }}{\text { Total number of seeds }} * 100 \\
& \text { (c) } \mathrm{Tol}=\frac{\text { PAE }+ \text { PSD }}{2} \\
& \text { (d) } \mathrm{HSI}=\log _{10} \frac{\mathrm{PAE}}{\mathrm{MDP}}
\end{aligned}
$$

Where MDP (Mean Development Period in days) is the average time taken for the bruchid insect to develop from egg to adult which is signified by the emergence of the adult from the seed;

$$
\text { (e) } \mathrm{MDP}=\frac{x_{1}+x_{2}+x_{3}+x_{4}}{4}
$$

where $x_{i}$ is the average development period for cumulative adult insects in each experimental replicate set up.

Data collection was terminated 60 days after insect infestation to avoid counting second-generation of emerging insects. Values from analysis above were used to group the accessions into bruchid tolerant and bruchid susceptible accessions.

\section{Morphological Evaluation of the Cowpea Lines}

Each accession was planted in $2 \mathrm{~kg}$ pots replicated 10 times. The pots were arranged at $40 \mathrm{~cm}$ equidistance from each other using randomized complete block design. The experiment was conducted in the screen house of IAR\&T, Ibadan, Oyo State (Latitude: $7^{\circ} 22^{\prime} 35.2^{\prime \prime} \mathrm{N}$, Longitude: $3^{\circ}$ $50^{\prime} 34.4^{\prime \prime}$ E) between January to April, 2017. General agronomic traits of cowpea were used for morphological characterization of the cowpea accessions as described by the International Board for Plant Genetic Resources (IBPGR, 1983). Data were collected on the qualitative characters (plant habit, terminal leaf shape, terminal leaflet base shape, terminal leaflet top shape, pigmentation, hairiness of plant, pod position with canopy, pod 
stripes, flower colour, pod curvature, seed colour, seed coat nature) and quantitative characters (terminal leaflet length, terminal leaflet width, terminal leaflet/width ratio, leaf petiole length, terminal leaflet petiole length, leaf rachis length, number of branches per plant on main steam, pod length, pod width, total number of pods per peduncle, total number of pods per plant, seed length, seed width, seed thickness).

\section{Data Analysis}

Qualitative and quantitative data from the replicates of accessions in the group were pooled together and statistically analysed using IBM SPSS version 25 (IBM Corp., Armonk, NY, USA). Independent sample t-test was used to compare values of the evaluated quantitative characters of the two groups assuming no variation between groups. Differences were considered significant at $5 \%$ significant level. Correlation between the characters measured with bruchid tolerance using Spearman's correlation was also done. Differentiating characters were subjected to stepwise multiple regression to determine the predictive ability at $p<0.05$.

\section{RESULTS}

\section{Bruchid Tolerance Evaluation and Groupings of Accessions}

Bruchid tolerance performance and grouping of evaluated cowpea accessions is presented in table 2. A total of 52 accessions of cowpea comprising of all the cowpea accessions (31) collected from IAR\&T and 21 accessions collected from IITA were susceptible to bruchid infestation. The susceptible accessions recorded between $80-$ $100 \%$ emergence of adult bruchid and $80-100 \%$ seed damage. Only eight accessions (TVu-11953, IT81D-1064, IT99K-429-2, IT81D-1032, IT97K-
499-2, IT97K-1042-8, IT97K-1042 and TVu2027) showed varied bruchid tolerance levels (Tol $=0-65 \%)$. Among the least bruchid tolerant, TVu-11953 and IT81D-1064 showed 10.37\% and $48.49 \%$ adult emergence, respectively. However, MDP for these two genotypes were 44 days and 35 days, respectively making TVu-11953 a better bruchid resistant than IT81D-1064. IT99K-429-2 was observed to have delayed the MDP to 47 days than both TVu-11953 and IT81D-1064 genotypes but showed a higher PAE of $57.88 \%$. Hence, 8 accessions were considered bruchid tolerant (HSI $=-0.63-0.25)$ with PSD between $40-66 \%$ while the remaining 52 accessions were considered bruchid susceptible (HSI $=0.40-0.64$ ) with PSD $>80 \%$ after the bruchid tolerance evaluation (Table 2).

\section{Qualitative and Quantitative Differences between Bruchid Tolerant and Susceptible Cowpeas}

Qualitative characters varied moderately within bruchid tolerant groups under study but no unique differences were observed between the bruchid tolerant and susceptible groups (Table 3). However, evaluation of quantitative characters between bruchid tolerant and susceptible groups revealed that all characters significantly differ between the two groups except the terminal leaflet width, number of branches per plant on the main stem and total number of pods per peduncle (Table 4). The highest significant variation was observed in the total number of pods per plant (Coefficient of Variation $(C V)=59.10, t=2.89, p$ $<0.01$ ) while total number of pods per peduncle shows the least morphological variation and no significant difference between the two groups (CV $=10.68, \mathrm{t}=0.00, p>0.05)$. 
Table 1: Names of Cowpea Accessions used in this Study and where they were sourced from.

\begin{tabular}{|c|c|c|c|c|c|}
\hline Sn & Accessions & Source & $\mathrm{Sn}$ & Accessions & Source \\
\hline 1 & $\mathrm{NG} / \mathrm{SA} / 07 / 167$ & IAR\&T & 31 & Ife-98-14 & IAR\&T \\
\hline 2 & $\mathrm{NG} / \mathrm{SA} / 07 / 159$ & IAR\&T & 32 & IT95K-193-12 & IITA \\
\hline 3 & NG/SA/01/09/008 & IAR\&T & 33 & IT93K-452-1 & IITA \\
\hline 4 & NG/SA/07/089 & IAR\&T & 34 & IT86D-719 & IITA \\
\hline 5 & Cowpea-2 & IAR\&T & 35 & IT98K-205-8 & IITA \\
\hline 6 & $\mathrm{NG} / \mathrm{SA} / 07 / 155$ & IAR\&T & 36 & IT97K-499-35 & IITA \\
\hline 7 & NG/SA/01/09/001 & IAR\&T & 37 & IT89KD-288 & IITA \\
\hline 8 & 311109 & IAR\&T & 38 & IT95-499-35 & IITA \\
\hline 9 & NG/SA/01/09/009 & IAR\&T & 39 & $\mathrm{TV} \times 3236$ & IITA \\
\hline 10 & NG/SA/07/083 & IAR\&T & 40 & IT90K-277-2 & IITA \\
\hline 11 & $\mathrm{NG} / \mathrm{AO} / 11 / 08 / 084$ & IAR\&T & 41 & IT84S-2246-4 & IITA \\
\hline 12 & NGB/06/041 & IAR\&T & 42 & IT90K-76 & IITA \\
\hline 13 & $\mathrm{NG} / \mathrm{AO} / 11 / 08 / 089$ & IAR\&T & 43 & IT90K-277-2 & IITA \\
\hline 14 & $\mathrm{NG} / \mathrm{SA} / 07 / 141$ & IAR\&T & 44 & IT90K-59 & IITA \\
\hline 15 & NG/SA/01/09/005 & IAR\&T & 45 & IT95K-222-3 & IITA \\
\hline 16 & NG/SA/07/135 & IAR\&T & 46 & IT97K-207-15 & IITA \\
\hline 17 & 304107 & IAR\&T & 47 & IT87S-1393 & IITA \\
\hline 18 & NG/SA/01/09/004 & IAR\&T & 48 & IT86D-498 & IITA \\
\hline 19 & NG/SA/07/132 & IAR\&T & 49 & TVu-11979 & IITA \\
\hline 20 & NG/SA/07/130 & IAR\&T & 50 & IT99K-494-6 & IITA \\
\hline 21 & $\mathrm{NGB} / 06 / 043$ & IAR\&T & 51 & IT81D-994 & IITA \\
\hline 22 & $\mathrm{NGB} / 06 / 110$ & IAR\&T & 52 & IT97K-499-8 & IITA \\
\hline 23 & NG/SA/01/09/015 & IAR\&T & 53 & TVu-11952 & IITA \\
\hline 24 & NG/SA/01/09/011 & IAR\&T & 54 & TVu-2027 & IITA \\
\hline 25 & Ife Brown & IAR\&T & 55 & IT81D-1032 & IITA \\
\hline 26 & Ife-98-12 & IAR\&T & 56 & IT81D-1064 & IITA \\
\hline 27 & Ife BPC & IAR\&T & 57 & IT97K-1042-8 & IITA \\
\hline
\end{tabular}

IAR\&T: Institute of Agricultural Research and Training, Moore Plantation, Oyo State; IITA: International Institute for Tropical Agriculture, Ibadan, Oyo State 
Table 2: Bruchid Tolerance Performance among 60 Cowpea Accessions

\begin{tabular}{|c|c|c|c|c|c|c|c|}
\hline Sn & Accessions & $\begin{array}{l}\text { MDP } \\
\text { (days) }\end{array}$ & $\begin{array}{c}\text { PAE } \\
(\%)\end{array}$ & $\begin{array}{c}\text { PSD } \\
(\%)\end{array}$ & $\begin{array}{l}\text { Tol } \\
(\%)\end{array}$ & HIS & Status \\
\hline 1 & NG/SA/07/167 & 28 & 100 & 100 & 100 & 0.55 & $\mathrm{~S}$ \\
\hline 2 & NG/SA/07/159 & 34 & 100 & 92.5 & 96.25 & 0.47 & $\mathrm{~S}$ \\
\hline 3 & NG/SA/01/09/008 & 28 & 100 & 90 & 95 & 0.55 & $\mathrm{~S}$ \\
\hline 4 & NG/SA/07/089 & 28 & 100 & 100 & 100 & 0.55 & $\mathrm{~S}$ \\
\hline 5 & Cowpea-2 & 29 & 100 & 80 & 90 & 0.54 & $\mathrm{~S}$ \\
\hline 6 & NG/SA/07/155 & 28 & 100 & 100 & 100 & 0.55 & S \\
\hline 7 & NG/SA/01/09/001 & 30 & 100 & 100 & 100 & 0.52 & $\mathrm{~S}$ \\
\hline 8 & 311109 & 29 & 100 & 100 & 100 & 0.54 & $\mathrm{~S}$ \\
\hline 9 & NG/SA/01/09/009 & 30 & 100 & 100 & 100 & 0.52 & S \\
\hline 10 & NG/SA/07/083 & 28 & 100 & 100 & 100 & 0.55 & $\mathrm{~S}$ \\
\hline 11 & $\mathrm{NG} / \mathrm{AO} / 11 / 08 / 084$ & 30 & 100 & 100 & 100 & 0.52 & $\mathrm{~S}$ \\
\hline 12 & NGB/06/041 & 28 & 100 & 100 & 100 & 0.55 & $\mathrm{~S}$ \\
\hline 13 & $\mathrm{NG} / \mathrm{AO} / 11 / 08 / 089$ & 37 & 100 & 100 & 100 & 0.43 & $\mathrm{~S}$ \\
\hline 14 & NG/SA/07/141 & 29 & 100 & 100 & 100 & 0.54 & $S$ \\
\hline 15 & NG/SA/01/09/005 & 38 & 100 & 90 & 95 & 0.42 & S \\
\hline 16 & NG/SA/07/135 & 32 & 100 & 100 & 100 & 0.49 & $\mathrm{~S}$ \\
\hline 17 & 304107 & 28 & 100 & 95 & 97.50 & 0.55 & $\mathrm{~S}$ \\
\hline 18 & NG/SA/01/09/004 & 28 & 100 & 100 & 100 & 0.55 & $\mathrm{~S}$ \\
\hline 19 & NG/SA/07/132 & 33 & 100 & 100 & 100 & 0.48 & $\mathrm{~S}$ \\
\hline 20 & NG/SA/07/130 & 30 & 100 & 97.50 & 98.75 & 0.52 & $\mathrm{~S}$ \\
\hline 21 & $\mathrm{NGB} / 06 / 043$ & 38 & 100 & 95 & 97.50 & 0.42 & $\mathrm{~S}$ \\
\hline 22 & NGB/06/110 & 30 & 100 & 92.50 & 96.25 & 0.52 & S \\
\hline 23 & NG/SA/01/09/015 & 29 & 100 & 100 & 100 & 0.54 & $\mathrm{~S}$ \\
\hline 24 & NG/SA/01/09/011 & 30 & 100 & 100 & 100 & 0.52 & $\mathrm{~S}$ \\
\hline 25 & Ife-brown & 23 & 100 & 100 & 100 & 0.64 & $\mathrm{~S}$ \\
\hline 26 & Ife-98-12 & 30 & 100 & 100 & 100 & 0.52 & $\mathrm{~S}$ \\
\hline 27 & Ife-BPC & 28 & 100 & 100 & 100 & 0.55 & $\mathrm{~S}$ \\
\hline 28 & Oloyin & 34 & 100 & 100 & 100 & 0.47 & S \\
\hline 29 & Erusu & 35 & 100 & 100 & 100 & 0.46 & S \\
\hline 30 & Modupe & 32 & 100 & 100 & 100 & 0.49 & $\mathrm{~S}$ \\
\hline 31 & Ife-98-14 & 29 & 100 & 100 & 100 & 0.54 & S \\
\hline 32 & IT95K-193-12 & 33 & 100 & 100 & 100 & 0.48 & $\mathrm{~S}$ \\
\hline 33 & IT93K-452-1 & 30 & 100 & 100 & 100 & 0.52 & $S$ \\
\hline 34 & IT86D-719 & 35 & 100 & 100 & 100 & 0.46 & $\mathrm{~S}$ \\
\hline 35 & IT98K-205-8 & 33 & 100 & 100 & 100 & 0.48 & S \\
\hline 36 & IT97K-499-35 & 36 & 100 & 100 & 100 & 0.44 & $\mathrm{~S}$ \\
\hline 37 & IT89KD-288 & 30 & 100 & 100 & 100 & 0.52 & $\mathrm{~S}$ \\
\hline 38 & IT95-499-35 & 32 & 100 & 100 & 100 & 0.49 & $\mathrm{~S}$ \\
\hline 39 & TVx3236 & 26 & 100 & 100 & 100 & 0.59 & $\mathrm{~S}$ \\
\hline 40 & IT90K-277-2 & 34 & 100 & 100 & 100 & 0.47 & $\mathrm{~S}$ \\
\hline 41 & IT84S-2246-4 & 35 & 100 & 100 & 100 & 0.46 & S \\
\hline 42 & IT90K-76 & 33 & 100 & 100 & 100 & 0.48 & S \\
\hline 43 & IT90K-277-2 & 34 & 100 & 100 & 100 & 0.47 & $\mathrm{~S}$ \\
\hline 44 & IT90K-59 & 33 & 100 & 100 & 100 & 0.48 & S \\
\hline 45 & IT95K-222-3 & 33 & 100 & 100 & 100 & 0.48 & S \\
\hline 46 & IT97K-207-15 & 35 & 100 & 100 & 100 & 0.46 & $\mathrm{~S}$ \\
\hline 47 & IT87S-1393 & 36 & 100 & 100 & 100 & 0.44 & $\mathrm{~S}$ \\
\hline 48 & IT86D-498 & 34 & 100 & 100 & 100 & 0.47 & S \\
\hline 49 & Tvu-11979 & 34 & 100 & 100 & 100 & 0.47 & $\mathrm{~S}$ \\
\hline 50 & IT99K-494-6 & 37 & 100 & 80 & 90 & 0.43 & $\mathrm{~S}$ \\
\hline 51 & IT81D-994 & 33 & 83.4 & 100 & 91.70 & 0.40 & S \\
\hline 52 & IT97K-499-8 & 39 & 64.88 & 57 & 60.94 & 0.22 & MR \\
\hline 53 & TVu-11952 & 32 & 98.43 & 100 & 99.22 & 0.49 & $\mathrm{~S}$ \\
\hline 54 & TVu-2027 & 42 & 74.44 & 66 & 70.22 & 0.25 & MR \\
\hline 55 & IT81D-1032 & 39 & 63.35 & 52 & 57.68 & 0.21 & MR \\
\hline 56 & IT81D-1064 & 35 & 48.49 & 50 & 49.25 & 0.14 & MR \\
\hline 57 & IT97K-1042-8 & 38 & 67.33 & 60 & 63.67 & 0.25 & MR \\
\hline 58 & TVu-11953 & 44 & 10.37 & 40 & 25.19 & -0.63 & $\mathrm{R}$ \\
\hline 59 & IT97K-1042 & 42 & 75.00 & 65 & 70 & 0.25 & MR \\
\hline 60 & IT99K-429-2 & 47 & 57.88 & 50 & 53.94 & 0.09 & MR \\
\hline
\end{tabular}

Abbreviations-MDP: media development period; PAE: percentage adult insect emergence; PSD: percentage seed damage; Tol: tolerance; HSI: host susceptibility index; S: susceptible genotype; MR: moderately resistant genotype; R: resistant genotype 
Table 3: Qualitative Characters observed in Bruchid Susceptible and Tolerant Cowpea Groups

\begin{tabular}{|c|c|c|c|}
\hline Characters & Tolerant Group (8) & Susceptible Group (52) & Remark \\
\hline PHB & Erect & Erect & ns \\
\hline TLS & Deltoid & Deltoid & ns \\
\hline TLBS & Acute/deltoid & Acute & ns \\
\hline TLTS & Attenuate & Attenuate & ns \\
\hline PIG & Absent & Absent & ns \\
\hline HPC & Absent & Absent & ns \\
\hline PPC & Above & Above & ns \\
\hline PSP & Absent & Absent & ns \\
\hline FLC & Purple/white & Purple/White & ns \\
\hline PDC & Curved/straight & Straight & ns \\
\hline SDC & $\begin{array}{l}\text { Mottled red/Red/Brown/White/ } \\
\text { Chocolate }\end{array}$ & Brown/White/Chocolate & ns \\
\hline SDCN & Rough/Smooth & Rough/Smooth & ns \\
\hline
\end{tabular}

Number of accessions in group in parenthesis. Abbreviations-PHB: plant habit; TLS: terminal leaf shape; TLBS: terminal leaflet base shape; ditto: terminal leaflet top shape; PIG: pigmentation; HPC: hairiness of plant; PPC: Pod position with canopy; PSP: pod stripes; FLC: flower colour; PDC: pod curvature; SDC: seed colour; SDCN: seed coat nature; ns: no significant difference between groups

Table 4: Quantitative Characters Evaluated on Bruchid Tolerant/Resistant and Susceptible Cowpea Groups

\begin{tabular}{lcccc}
\hline Characters & Tolerant Group $(8)$ & Susceptible Group (52) & CV & t-test \\
\hline TLL & $15.50 \pm 1.48$ & $13.51 \pm 0.77$ & 17.74 & $4.88^{*}$ \\
TLW & $8.51 \pm 0.70$ & $8.07 \pm 1.11$ & 17.59 & 1.22 \\
TLR & $1.94 \pm 0.21$ & $1.59 \pm 0.12$ & 13.40 & $4.07^{*}$ \\
LPL & $8.82 \pm 2.44$ & $11.43 \pm 0.82$ & 23.06 & $2.28^{*}$ \\
TLPL & $9.62 \pm 2.46$ & $12.04 \pm 0.84$ & 22.69 & $2.51^{*}$ \\
LRL & $18.44 \pm 4.90$ & $23.47 \pm 1.66$ & 23.70 & $2.62^{*}$ \\
BPS & $15.20 \pm 4.60$ & $12.75 \pm 3.28$ & 29.84 & 1.33 \\
PDL & $7.08 \pm 0.29$ & $11.59 \pm 0.38$ & 26.83 & $14.03^{* *}$ \\
PDW & $0.59 \pm 0.11$ & $0.80 \pm 0.07$ & 21.01 & $4.19^{* *}$ \\
PPP & $2.00 \pm 0.00$ & $2.25 \pm 0.46$ & 10.68 & 0.00 \\
PPPT & $5.25 \pm 1.14$ & $10.17 \pm 5.85$ & 59.10 & $2.89^{*}$ \\
SDL & $9.66 \pm 1.27$ & $7.46 \pm 0.51$ & 17.56 & $4.87^{* *}$ \\
SDW & $7.57 \pm 0.39$ & $5.77 \pm 0.24$ & 15.91 & $12.55^{* *}$ \\
SDTK & $6.24 \pm 0.51$ & $4.14 \pm 0.53$ & 21.56 & $9.87^{* *}$ \\
100-SDWT & $26.40 \pm 1.63$ & $14.57 \pm 1.22$ & 30.74 & $18.78^{* *}$ \\
\hline
\end{tabular}

$* p<0.05 ; * * p<0.01$; Values are represented in mean \pm SD of group; Number of accessions in group in parenthesis. Abbreviations-TLL: terminal leaflet length (cm); TLW: terminal leaflet width (cm); TLR: terminal leaflet/width ratio; LPL: leaf petiole length (cm); TLPL: terminal leaflet petiole length (cm); LRL: leaf rachis length $(\mathrm{cm})$; BPS: number of branches per plant on main steam; PDL: pod length; PDW: pod width; PPP: total number of pods per peduncle; PPPT: total number of pods per plant; SDL: seed length (mm); SDW: seed width (mm); SDTK: seed thickness (mm); 100-SDWT: 100 seed weight (g); CV: coefficient of variation (\%); ns: no significant difference between groups 


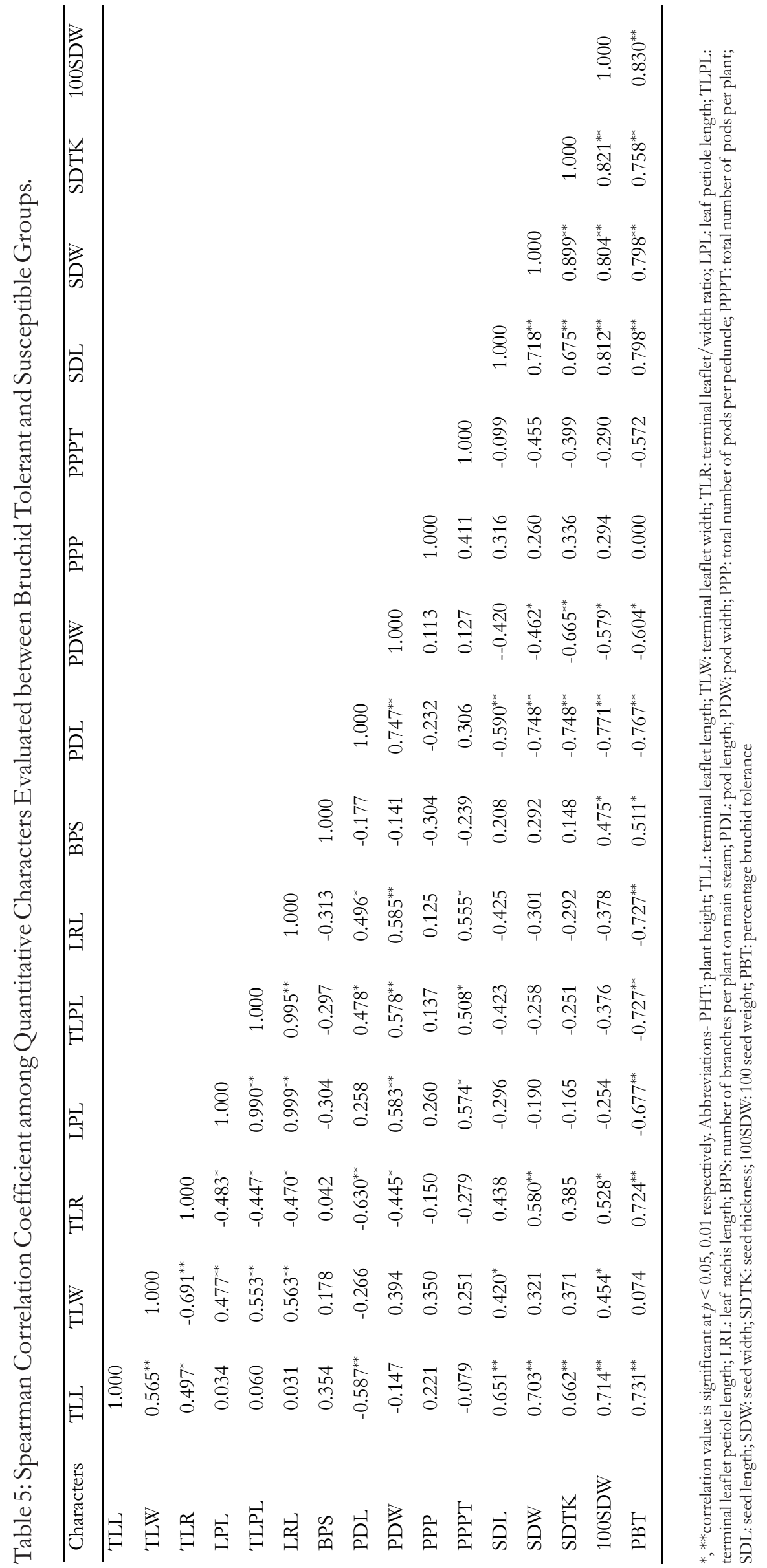




\section{Relationship with Bruchid Tolerance Status and Morphological Characters}

Correlation analysis between all quantitative characters evaluated and bruchid tolerance revealed significant negative correlation between bruchid tolerance and terminal leaflet petiole length $(\mathrm{r}=-0.73, p<0.01)$, leaf rachis length $(\mathrm{r}=$ $0.73, p<0.01)$, and pod length $(\mathrm{r}=-0.77, p<0.01)$. on the other hand, bruchid tolerance was significantly positively correlated with terminal leaflet length ( $\mathrm{r}=0.73, p<0.01)$, terminal leaflet/width ratio $(\mathrm{r}=0.72, p<0.01)$ and seed characters which include seed length $(\mathrm{r}=0.80, p<$ $0.001)$, seed width $(\mathrm{r}=0.80, p<0.001)$, seed thickness $(\mathrm{r}=0.76, p<0.01)$ and seed weight $(\mathrm{r}=$ $0.83, p<0.01)$. However, stepwise multiple regression model analysis showed that no character was found to significantly predict bruchid tolerance from further regression analysis of characters evaluated with regard to bruchid tolerance (Table 5).

\section{DISCUSSION}

The suitability of the food material for pest is determined based on the growth index as measured by HSI, a key parameter for insect growth and development. Genotypes with low HSI are considered as resistant while those with high HSI as susceptible. It was based on the assumption that insect progeny development would take a longer time in the resistant seed than in the susceptible seed (Soumia et al., 2017), thus leading to fewer insect progenies emerging from resistant seeds when compared to the susceptible seeds. It has been reported that susceptibility to pest attack by legumes is related to the rate of insect growth success and time from egg to adult (Kosini et al., 2017). The cowpea accessions evaluated varied in HSI in this study, with TVu11953 having the lowest HSI, as it showed a lower percentage of emergence periods in adults, whereas Ife brown had the highest HSI showing higher adult emergence over a shorter time interval in the study. This indicates that TVu11953 was the least bruchid tolerant and Ife brown the highest bruchid tolerant. Kosini et al. (2017) in their study reported that varieties with high percentage adult emergence and short developmental period may be severely damaged but those that allow low adult emergence and long generation times may be minimally damaged.
Resistance breakdown is a major problem when using host resistance to pest as an alternative method of pest control. Several of the bruchid tolerant cowpea accessions collected for the study were susceptible after the bruchid bioassay. One of such accession used in the study, TVu-2027, was previously reported by Jackai and Singh (1988) as the only accession in IITA's germplasm collection showing resistance to bruchid infestation. It was discovered almost 30 years ago and has since been used widely for bruchid resistance breeding programmes. Later, Singh and Singh (1990) reported two other accessions to TVu-2027, TVu-11952 and TVu-11953 with moderate tolerance. Ofuya and Credland (1995) in their study evaluated the relative susceptibilities of cowpea varieties including Ife Brown, TVu-2027, and IT84S-2246-4 and found that TVu-2027 showed lower percentage adult emergence while Ife brown was regarded as the most susceptible. These accessions, TVu 2027 and Ife brown, have been used for breeding programmes at IITA as a bruchid resistant and susceptible references, respectively. The tolerance evaluation also showed that IT84S-2246-4 was susceptible to the bruchid infestation. However, this was not in accordance with IITA annual report (IITA, 2004). Dugje et al. (2009) also reported that the cowpea accession (IT84S-2246-4) shows moderate tolerance to bruchid infestation. The present study revealed that there was no bruchid resistant accession among samples from IAR\&T cowpea accessions (sampled landrace collected from exploration) used in this study, an implication that most of the Nigerian cultivars/landraces were susceptible to bruchid infestation as at the time of this study.

The need to identify and breed alternative sources for bruchid resistance in cowpea cannot be overestimated. Variability in the species selection for insect resistance is an important tool in breeding programs and this depends on the cultivar characteristics which may include a simple phenotypic appearance from the nature of leaf surface to grain or fruit characters which include the nature and/or biochemical factors of the seeds etc (Amusa et al., 2014). Phenotypic descriptors are necessary for assessing the genetic variation of crop species for the adequate investigations of the genetic variability in germplasm collections, thereby providing 
valuable information to conservation efforts and breeding programs (Franco et al., 2005; Laurentin, 2009). Although, variations were observed in qualitative characters among sampled accessions, these variations were not significantly different between the bruchid tolerance and susceptible cowpea groups. The absence of discriminating qualitative characters between the tolerant groups implies that bruchid resistance may not be dependable on observable characters in cowpea, example is the seed coat roughness and smoothness theory for bruchid resistance as opined by Magbo et al., (2014), Seram et al., (2016) and Soumia et al., (2017).

Several authors have attributed bruchid tolerance to seed characteristics which include seed coat texture, seed size, seed colour and seed thickness (Messina and Renwick, 1985; Mei et al., 2009; Chakraborty and Mondal, 2016). This does not only affect the tolerance of the seed to developing bruchid larvae but also reduce oviposition preference of the female bruchids (Amusa et al., 2013). This study reported that larger seeds with smooth surface were highly preferred by the pest as they provided more surface area for oviposition, ample food and space for the development of the larvae. Seed characters including seed length, seed width, seed thickness and 100 seed weight showed positive significant correlation with bruchid tolerance of the accessions in this study. The regression analysis however showed that the seed characters were not good predictors or identifiers for bruchid tolerance. This corroborates with previously reported works that bruchid tolerance is not influenced by seed characters (Maina et al., 2012; Cruz et al., 2016). This may be as a result of low genetic variability within the germplasm.

\section{CONCLUSION}

This study evaluated the phenotypic variation in the qualitative and quantitative characteristics of 60 cowpea accessions in relation to their bruchid tolerance status. Such information could be used as a preliminary indication for the identification of cowpea accessions tolerant to bruchid. Although, the study found significant correlations among some characters and bruchid tolerance, the small differences observed between bruchid susceptible and tolerant genotypes were not discriminatory enough to effectively predict tolerance to bruchids. These traits still need to be further investigated, to explore other options for better identification of bruchid tolerance within the cowpea germplasm.

\section{ACKNOWLEDGEMENTS}

The authors acknowledge the International Institute of Tropical Agriculture, Ibadan and Institute of Agricultural Research and Training, (IAR\&T), Moor Plantation, Ibadan, Nigeria for providing the seeds of the accessions and IAR\&T for allowing the use of their facilities for the study.

\section{REFERENCES}

Amusa, O.D., Ogunkanmi, L.A., Bolarinwa, K.A. and Ojobo, O. 2013. Evaluation of four cowpea lines for bruchid (Callosobruchus maculatus) tolerance. Journal of Natural Sciences Research, 3(11): 46-52.

Amusa, O.D., Ogunkanmi, L.A., Adetumbi, J.A., Akinyosoye, S.T., Bolarinwa, K.A. and Ogundipe, O.T. 2014. Assessment of bruchid (Callosobruchus maculates) tolerance of some elite cowpea (Vigna unguiculata) varieties. Journal of Agriculture and Sustainability, 6(2): 164-178.

Amusa, O.D., Ogunkanmi, L.A., Adetumbi, J.A., Akinyosoye, S.T., and Ogundipe, O.T. 2019. Morpho-genetic variability in $F_{2}$ progeny cowpea genotypes tolerant to bruchid (Callosobruchus maculatus). Journal of Agricultural Sciences, 64(1): 53-68.

Chakraborty, S. and Mondal, P. 2016. Physiochemical parameters of pulses affecting the bruchid (Callosobruchus chinensis Linn.) infestation. Asian Journal of Science and Technology, 7(3): 2554-2560.

Cruz, P.S., de Sa, L.F.R., Santos, L.A., Gravina, G.A., Carvalho, A.O., Fernandes, K.V.S., Filho, F.R.F., Gomes, V.M. and Oliveira, A.E.A. 2016. Evaluation of resistance in different cowpea cultivars to Callosobruchus maculatus infestation. Journal of Pest Science, 89(1): 117-128.

Dugje, I.Y., Omoigui, L.O., Ekeleme, F., Kamara, A.Y. and Ajeigbe, H. 2009. Farmers' guide to cowpea production in West Africa. International Institute of Tropical Agriculture Ibadan (IITA), Ibadan, Nigeria, 20pp.

Franco, J., Crossa, J., Taba, S. and Shands, H. 2005. 
A sampling strategy for conserving genetic diversity when forming core subsets. Crop Science, 45: 1035-1044.

IBPGR (International Board for Plant Genetic Resources) 1983. Descriptors for Cowpea. In: CGIAR (ed). AGPG:IBPGR/82/80, Rome. 29pp.

IITA 2004. International Institute for Tropical Agriculture. Improving and intensifying Cereal-Legume Systems in the moist and dry savannah of West and Central Africa, Annual Report, International Institute of Tropical Agriculture, Ibadan, Nigeria.

IITA 1990. International Institute of Tropical Agriculture. Advanced research confronts intractable cowpea pests, Gatisby Charitable Foundation: Agricultural Research Project

Jackai, L.E.N. and Singh, S.R. 1988. Screening techniques for host plant resistance to cowpea insect pests. Trop. Grain Legume Bullet, 35: 2-18.

Keneni, G., Bekele, E., Getu, E., Imtiaz, M., Damte, T. and Mulatu B. 2011. Breeding food legumes for resistance to storage insect pests: potential and limitations. Sustainability, 3(9): 1399-1415.

Kosini, D., SaidouM C. and Nukenine, E.N. 2017. Physico-chemical properties and resistance of ten bambara groundnut (Vigna subterranea) varieties to attack by Callosobruchus maculatus (Fabricius) (Coleoptera: Chrysomelidae) in the Sudano-Sahelian and Sudano-Guinean zones of Cameroon. Journal of Experimental Agriculture International, 15(1):1-14.

Laurentin, H. 2009. Data analysis for molecular characterization of plant genetic resources. Genetic Resources and Crop Evolution, 56: 277 292

Magbo, T.C., Okeke, T.E. and Akunne, C.E. 2014. Studies on the resistance of cowpea seeds (Vigna unguiculata) to weevil (Callosobruchus maculatus) infestation. American Journal of Zoological Research, 2(2): $37-40$

Maina, Y.T., Mbaya, A.M. and Mailafiya, D.M. 2012. Susceptibility of six local and four improved cowpea cultivars to Callosobruchus maculatus (F.) (Coleoptera: Bruchidae) infestation in North Eastern Nigeria. Journal of Environmental Issues and
Agriculture in Developing Countries, 4(1): 31 37.

Mei, L., Cheng, X.Z., Wang, S.H., Wang, L.X., Liu, C.Y., Sun, L., Xu, N., Humphry, M.E., Lambrides, C.J., Li, H.B., and Liu, C.J. 2009. Relationship between bruchid resistance and seed mass in mungbean based on QTL analysis. Genome, 52: 589-596.

Messina, F.J. and Renwick, J.A.A. 1985. Resistance to Callosobruchus maculatus (Coleoptera: Bruchidae) in selected cowpea lines. Environmental Entomology, 14(6): 868-872.

Ofuya, T.I. and Credland, P.F. 1995. Responses of three populations of the seed beetle, Callosobruchus maculatus (F.) (Coleoptera: Bruchidae), to seed resistance in selected varieties of cowpea, Vigna unguiculata (L.) Walp. Journal of Stored Product Research, 31: 17-27.

Olakojo, S.A., Ayanwole, J.A. and Obasemola, V.I. 2007. Laboratory screening of seeds of some cowpea cultivars (Vigna unguiculata) for tolerance to cowpea beetles (Callosobruchus maculatus) in a hot humid environment. American-Eurasian Journal Agricultural of Environmental Sciences, 2(5): 528-533.

Singh, B.B. and Singh, S.R. 1990. Breeding for bruchid resistance in cowpea. In: Bruchids and Legumes: Economics, Ecology and Co-evolution, K. Fujii, A.M.R. Gatehouse, C.D. Johnson, R. Mitchel, T. Yoshida (Editors). Proceedings of the Second International Symposium on Bruchids and Legumes (ISBL-2). Okayama, Japan. 407pp.

Seram, D., Senthil, N., Pandiyan, M. and Kennedy, J.S. 2016. Resistance determination of a South Indian bruchid strain against rice bean landraces of Manipur (India). Journal of Stored Product Research, 69: 199206

Soumia, P.S., Srivasstava, C., Guru, P.P. and Subramanian. S. 2017. Varietal preference of pulse beetle, Callosobruchus maculatus (F.) in greengram. Indian Journal of Entomology, 79(1): 86-91. 